Revista lus et Praxis, Año 19, № 2, 2013, pp. 53 - 84

ISSN 0717 - 2877

Universidad de Talca - Facultad de Ciencias Jurídicas y Sociales

"Responsabilidad del Estado por conductas injustificadamente erróneas

o arbitrarias del Ministerio Público: análisis comparativo y jurisprudencial"

Pedro P. Ballivian Searle

\title{
RESPONSABILIDAD DEL ESTADO POR CONDUCTAS INJUSTIFICADAMENTE ERRÓNEAS O ARBITRARIAS DEL MINISTERIO PÚBLICO: ANÁLISIS COMPARATIVOY JURISPRUDENCIAL*
}

\author{
STATE RESPONSIBILITY FOR ERRONEOUS OR \\ ARBITRARY CONDUCT UNREASONABLY PUBliC MinISTRY: \\ COMPARATIVE ANALYSIS AND JURISPRUDENTIAL
}

Pedro P. Ballivian Searle*

\begin{abstract}
RESUMEN
El presente trabajo tiene por objetivo analizar la responsabilidad del Estado por errores judiciales, consagrada en el artículo 19 Nº 7 letra i) de la Constitución, y solucionar los problemas para su corrección o realización, ya que ésta no ha cumplido con su objeto, es decir, reparar los daños a las personas afectadas. Lo anterior, dada la restrictiva interpretación de la norma por parte de la Corte Suprema. Fruto de ello es que se plantea como norma eficaz para obtener la reparación en un proceso penal, la norma consagrada en el artículo $5^{\circ}$ de la Ley Orgánica Constitucional del Ministerio Público, que establece un régimen de responsabilidad estatal por las actuaciones erróneas o arbitrarias del Ministerio

Público. El trabajo analizará los distintos tipos de responsabilidad existentes, funciones y principios a los que debe ceñirse el órgano persecutor en su actuar, junto con un análisis de ambas normas en cuestión, apoyado en la jurisprudencia de la Corte Suprema en este asunto.
\end{abstract}

ABSTRACT

This paper aims to analyze the State's responsibility for mistakes trial embodied in Article $19 \mathrm{~N}^{\circ} 7$ letter i) of the Constitution and solve problems for correction or completion, as it has not fulfilled its purpose due to repair damage affected. This, for the restrictive interpretation of the law by the Supreme Court. The result of the above is that it poses as a rule effective in obtaining compensation in criminal proceedings,

the rule embodied in Article 5 of the Constitutional Organic Law of the Public Ministry, which establishes a system of state responsibility for the actions wrong or arbitrary prosecutors. The paper will analyze the various existing liability, functions and principle to which the body must adhere persecutor in his actions, together with an analysis of both standards in question, supported by the case law of the Supreme Court in this matter.

* Trabajo recibido el 21 de marzo y aprobado el 20 de junio de 2013.

** Estudiante de Derecho Universidad de los Andes. Correo electrónico: ppballivian@miuandes.cl. 


\begin{abstract}
Palabras Clave
Indemnización, Error judicial, Responsabilidad del Estado, Ministerio Público, Injustificadamente erróneo o arbitrario

KEYWORDS

Compensation, Miscarriage of justice, State responsibility for, Public Porsecutor, Unjustifiably erroneous or arbitrary
\end{abstract}

\title{
INTRODUCCIÓN
}

El artículo 19 № 7 letra i) de la Constitución Política de Chile (en adelante CPR), contempla la llamada acción de indemnización por error judicial ${ }^{1}$, la cual, como lo dice su propio nombre, tiene por objeto indemnizar a las personas que han sido afectadas en un proceso judicial penal. En otras palabras reconoce la responsabilidad del Estado-Juez².

La responsabilidad del Estado no es un tema nuevo, ni tampoco algo de lo que se hablará por primera vez en esta ocasión. Sabemos que el régimen de responsabilidad estatal es amplio y contempla variadas manifestaciones, y que es un principio de todo Estado de Derecho el deber de responder, pagar, por el incumplimiento de una determinada obligación o por los daños causados -tanto patrimoniales como morales- frente a los particulares.

En el caso antes nombrado se contempla la posibilidad de indemnizar a aquellas personas a las que se les han visto vulnerados sus derechos en un proceso penal. Es la única norma en Chile que contempla la responsabilidad del Estado como juez, que frente a errores cometidos por los jueces, y que afecten a los imputados por un crimen o simple delito, el Estado debe de responder.

El problema es que lo existente es sólo una apariencia de responsabilidad del Estado dentro de los procesos penales, ya que dicho precepto es ineficaz y en la realidad no logra el objeto buscado por tal norma. Esto se manifiesta en las solo cuatro sentencias acogidas en casi 100 años de vigencia de la disposición ${ }^{3}$.

\footnotetext{
${ }^{1}$ CPR, art. $19 \mathrm{~N}^{\circ} 7$ letra i).- Una vez dictado sobreseimiento definitivo o sentencia absolutoria, el que hubiere sido sometido a proceso o condenado en cualquier instancia por resolución que la Corte Suprema declare injustificadamente errónea o arbitraria, tendrá derecho a ser indemnizado por el Estado de los perjuicios patrimoniales o morales que haya sufrido. La indemnización será determinada judicialmente en un procedimiento breve y sumario y en él la prueba se apreciará en conciencia.

2 Hernández Emparanza, Domingo, "Error judicial: ensayo de interpretación constitucional", lus et Praxis, 1999, vol. 5, pp. 461-472.

${ }^{3}$ Salinas Gómez con Fisco, Corte Suprema, 14 de noviembre de 1985, Rol № 24.518, Gaceta Jurídica No 65, 1985, pp. 71-74.

Araya Molina, Eugenio, Corte Suprema, 25 de julio de 1989, Rol № 23.833, Revista de Derecho y Jurisprudencia, Tomo 86, 1989, $2^{\text {a }}$ parte, sección 5a, pp. 85-91.

Vegas Rojas, Jorge del Carmen, Corte Suprema, 5 de diciembre de 1990, Rol № 27.662, Revista de Derecho y Jurisprudencia, Tomo LXXXVII, mayo-agosto de 1990, sección 5ª ${ }^{a}{ }^{a}$ parte, pp. 184-189.

Yáñez Pavez María, Corte Suprema, 11 de agosto de 2011, Rol № 5411-2010.
} 
También la doctrina sostiene lo mismo, es decir, que dicha norma no ha cumplido con su objetivo, por distintas razones que se analizarán en su momento ${ }^{4}$.

Frente a esta aparente o posible irresponsabilidad del Estado en materia penal (la norma constitucional sólo se aplica a los procesos penales, y el presente trabajo sólo se abocará a la responsabilidad estatal dentro del mismo ámbito), está presente en nuestro ordenamiento jurídico el artículo $5^{\circ}$ de la Ley Orgánica Constitucional del Ministerio Público (Ley $\left.N^{\circ} 19.640\right)^{5}$, que establece el deber del Estado de responder de las conductas injustificadamente erróneas o arbitrarias que cometa el Ministerio Público. Por lo tanto, frente a la ineficacia de la norma constitucional, y con el objeto de hacer efectiva la responsabilidad estatal en este tema, en ciertos casos (no todos), el artículo $5^{\circ}$ de la Ley No 19.640 (en adelante "LOCMP"), es la correcta manera de buscar la indemnización por parte del afectado, ya que el Estado tiene el deber de indemnizar por las conductas realizadas por el Ministerio Público que causen daño a las personas, sea el imputado en el proceso u otra persona que no tenga participación en él.

En otras palabras, en razón de que la norma constitucional de indemnización por error judicial no ha mostrado ser eficaz para resarcir daños o determinar responsabilidad, la manera adecuada de obtener una indemnización en materia penal, por los errores injustificadamente erróneos o arbitrarios que se cometan, es haciendo uso del artículo $5^{\circ}$ de la LOCMP, es decir, la responsabilidad estatal por las conductas de este tipo cometidas por el Ministerio Público ${ }^{6}$.

\footnotetext{
${ }^{4}$ Son varios los autores que hacen una crítica a la norma constitucional. Entre ellos cabe destacar las siguientes obras: CALDERA, Hugo, "Interpretación que la Corte Suprema ha dado a la norma constitucional sobre indemnización por error judicial", Gaceta Jurídica № 70, p. 10, y Revista de Derecho Público, Facultad de Derecho, U. de Chile, № 37-38, 1985, pp. 345-364. García Mendoza, Hernán, La responsabilidad extracontractual del Estado: indemnización del error judicial, Editorial Jurídica ConoSur Ltda., Santiago, 1997, t. I, pp. 227-460. GARRIDO MonTt, Mario, "La indemnización por error judicial en Chile", Ius et Praxis, 1999, vol. 5, pp. 473-482. HeRnÁnDEZ, "Error judicial", cit. nota № 2, pp. 461-472. Pereira Anabalón, Hugo, "La responsabilidad del Estado por error judicial", Gaceta Jurídica, № 275, 2003, pp. 7-15. PRECHT PIZARRO, Jorge, "Resolución injustificadamente errónea o arbitraria en la indemnización por error judicial", Estudios Constitucionales, 2004, vol.2, número 001, pp. 175-180. ZúNIIGA URBINA, Francisco, "La acción de indemnización por error judicial. Reforma Constitucional. Regulación Infraconstitucional y jurisprudencia", Estudios Constitucionales, 2008, vol. 2, pp. 15-41.

${ }^{5}$ Artículo $5^{\circ}$ Ley $N^{0}$ 19.640.- El Estado será responsable por las conductas injustificadamente erróneas o arbitrarias del Ministerio Público. La acción para perseguir esta responsabilidad patrimonial prescribirá en cuatro años, contados desde la fecha de la actuación dañina. En todo caso no afectara a la responsabilidad que pudiese afectar al fiscal o funcionario que produjo el daño, y, cuando haya mediado culpa grave o dolo de su parte, al derecho del Estado para repetir en su contra.

${ }^{6}$ Tesis planteada por el profesor Natalio Vodanovic en su obra Comentario de jurisprudencia: Aspectos de las indemnizaciones por error judicial y por conductas erróneas del Ministerio Público, con el nuevo sistema procesal penal. En: https:/www.cde.cl/wps_migrated/wcm/connect/022b42004fbf778 2baffbb46ce4e7365/18.pdf?MOD=AJPERES [visitado el 16/10/2012].
} 
Con el objeto de poder comprender mayormente el tema a tratar, en primer lugar, es necesario establecer los límites de la discusión, para que así no haya dudas acerca del mismo:

- Estamos frente a dos tipos de responsabilidades del Estado. Por un lado, la responsabilidad del Estado-Juez ("acción de indemnización por error judicial") y, por otro, una responsabilidad de un órgano de la administración del Estado.

- Sin perjuicio de lo anterior, el objeto y el ámbito en donde se dan son el mismo: se busca obtener una indemnización y siempre por errores cometidos dentro de un proceso penal.

- El presente trabajo sólo se abocará al deber del Estado de responder frente a estas situaciones, sin ninguna mención a otro tipo de responsabilidad, como puede ser la responsabilidad funcionaria de los fiscales, o de cualquier otro interviniente en el proceso.

\section{ResponsabiLIDAD DEL ESTADO}

\subsection{Concepto general de responsabilidad}

Por responsabilidad se entiende generalmente la obligación que tiene un determinado sujeto de reparar o indemnizar a aquel que le haya causado un daño o fruto de un incumplimiento.

Así tenemos innumerables definiciones sobre lo que se entiende por responsabilidad. Para la Real Academia de la Lengua Española, responsabilidad es "Deuda, obligación de reparar y satisfacer, por sí o por otra persona, a consecuencia de un delito, de una culpa o de otra causa legal" (22 a edición, año 2001). Rodríguez Grez, siguiendo esta concepción de responsabilidad, la define como "un deber jurídico de reparar los daños o perjuicios que producen con ocasión del incumplimiento de una obligación"7.

Según la opinión del profesor Mundaca ${ }^{8}$ dichos conceptos llevan a que el fundamento de la responsabilidad sea la culpabilidad, por lo que donde no se dé negligencia ni malicia, no habrá responsabilidad, por lo tanto tampoco obligación de reparar el daño.

Dicha posición es criticada por autores como Soto Kloss, que fundamenta la responsabilidad en la idea de restitución, concluyendo que la obligación de reparar no nace de una falta, ya que no existiendo ésta el desequilibrio y la ruptura de justicia se producirían igual, siendo necesario restablecerlo. Por lo

\footnotetext{
7 Rodríguez, Pablo, Responsabilidad Extracontractual, Santiago, Editorial Jurídica de Chile, 1999, p. 11.

${ }^{8}$ MundaCA, Hans, La responsabilidad del Estado por falta de servicio, Editorial Libromar Ltda., Valparaíso, 2001, p. 19.
} 
tanto, desde que nace el daño, el perjuicio que significa una injusticia, nace la obligación de ser reparada9.

Un concepto más amplio, es el que da Zúñiga ${ }^{10}$, al definirla como "el conjunto de reglas que determinan la persona a la que el ordenamiento jurídico ordena reparar un daño". Dicho concepto es compartido por nuestra parte, al ser una definición amplia, y capaz de cubrir todo tipo de responsabilidad.

Siguiendo a este autor ${ }^{11}$, de acuerdo al sujeto responsable, se puede clasificar la responsabilidad en:

$>$ Responsabilidad del Estado: la cual consagra principalmente la obligación que tiene el ente estatal de responder por los daños causados. En nuestro ordenamiento jurídico se encuentra consagrada este tipo de responsabilidad, principalmente (pero no exclusivamente), en los artículos $6^{\circ}, 7^{\circ}$ y 38 inciso $2^{\circ}$ de la CPR ${ }^{12}$.

$>$ Responsabilidad de los particulares: la cual puede dar origen a la responsabilidad civil y a la responsabilidad penal común. Según las reglas generales del Derecho, para que se configure este tipo de responsabilidad es necesaria la concurrencia de cuatro elementos: daño, culpa o dolo, relación de causalidad entre el daño y la culpa o dolo, y capacidad.

Para la determinación de la persona responsable, o determinación de la responsabilidad penal, se encuentran los siguientes sistemas:

- Responsabilidad subjetiva o aquiliana: que según las palabras de Zúñiga "este sistema de responsabilidad se basa en la imputación, ya sea a título de culpa o dolo". Y luego dice que funciona con base en el siguiente esquema:

\footnotetext{
${ }_{9}^{9}$ Mundaca, Hans, La Responsabilidad, cit. nota n. 8, pp. 19-20.

${ }^{10}$ ZúNIIGA URBINA, Francisco, "La acción de indemnización por error judicial. Reforma Constitucional. Regulación Infraconstitucional y jurisprudencia", Estudios Constitucionales, 2008, vol. 2, pp. 17-18.

11 ZúÑIGA, Francisco, "La acción", cit. nota n. 10, pp. 18-22.

${ }^{12}$ Artículo $6^{\circ}$ CPR.- Los órganos del Estado deben someter su acción a la Constitución y a las normas dictadas conforme a ella, y garantizar el orden institucional de la República. Los preceptos de esta Constitución obligan tanto a los titulares o integrantes de dichos órganos como a toda persona, institución o grupo. La infracción de esta norma generará las responsabilidades y sanciones que determine la ley. Artículo $7^{\circ}$ CPR.- Los órganos del Estado actúan válidamente previa investidura regular de sus integrantes, dentro de su competencia y en la forma que prescriba la ley. Ninguna magistratura, ninguna persona ni grupo de personas pueden atribuirse, ni aun a pretexto de circunstancias extraordinarias, otra autoridad o derechos que los que expresamente se les hayan conferido en virtud de la Constitución o las leyes. Todo acto en contravención a este artículo es nulo y originará las responsabilidades y sanciones que la ley señale.

Artículo 38 inciso $2^{\circ}$ CPR.- Cualquier persona que sea lesionada en sus derechos por la Administración del Estado, de sus organismos o de las municipalidades, podrá reclamar ante los tribunales que determine la ley, sin perjuicio de la responsabilidad que pudiere afectar al funcionario que hubiere causado el daño.
} 
"si una persona sufre un daño, deberá asumirlo, salvo que el autor del daño lo provoque a título de culpa o dolo".

- Responsabilidad objetiva: según el profesor Cordero Vega ${ }^{13}$ es aquella en donde "se debe responder por toda lesión que se ocasione en un derecho, independientemente de la naturaleza del acto generador del daño".

\subsection{Tipos de responsabilidad del Estado}

Como se señaló anteriormente, la responsabilidad estatal está plenamente reconocida en todos los ordenamientos jurídicos, incluido el nuestro, y nadie puede plantear hoy en día que el Estado es irresponsable por sus actos ante los particulares ${ }^{14}$.

Así también lo señala el autor Francisco Zúñiga ${ }^{15}$, al decir que el fundamento de la responsabilidad del Estado es el Estado de Derecho y sus presupuestos. Establece que plantear la idea un Estado irresponsable va contra sus propios términos. Finalmente, anota la idea de que el "Estado tiene la obligación de reparar pecuniariamente de modo de restablecer la situación patrimonial que con anterioridad al hecho o acto ilícito, tenía el damnificado, o sea, que haga desaparecer los efectos de la lesión sufrida por alguien en su patrimonio".

Por lo tanto, hoy en día es claro que para la existencia de un Estado de Derecho es necesario que el mismo Estado reconozca y haga efectiva su responsabilidad.

Habiendo reconocido la existencia de la responsabilidad patrimonial estatal, ésta puede tomar distintos tipos se facetas, a saber:

$>$ Responsabilidad del Estado Legislador ${ }^{16}$.

Se configura en los casos en que la ley, el acto legislativo propiamente tal, adolece de inconstitucionalidad, por lo que va a establecer lesiones antijurídicas o injustas a una persona o grupo de personas, imponiendo cargas especiales o limitando el ejercicio de derechos fundamentales ${ }^{17}$.

$>$ Responsabilidad del Estado Administrador ${ }^{18}$.

Es aquella propia de los actos de administración del Estado (entes de la administración del Estado) que en su actuar causan un daño o perjuicio. Den-

\footnotetext{
${ }^{13}$ Cordero, Luis, La responsabilidad de la administración del Estado, $2^{\text {a }}$ ed., Editorial LegalPublishing, Santiago, 2010, p. 48.

${ }^{14}$ García Mendoza, Hernán, La responsabilidad extracontractual del Estado: indemnización del error judicial, Editorial Jurídica ConoSur Ltda., Santiago, 1997, t. I, pp. 227-460, pp. 3-8.

${ }^{15}$ ZÚÑIGA, Francisco, "La acción", cit. nota n. 10, p. 21.

${ }^{16}$ García, Hernán, La responsabilidad, cit. nota n. 14, pp. 9-49.

17 ZúÑIGA, Francisco, "La acción", cit. nota n. 10, pp. 22-23.

${ }^{18}$ García, Hernán, La responsabilidad, cit. nota n. 14, pp. 51-221.
} 
tro de ésta, se pueden reconocer tres doctrinas, tres visiones diferentes, que estructuran la responsabilidad:

- Responsabilidad objetiva absoluta, la que según Cordero Vega es aquella en que la "Administración debe responder por toda lesión que ocasione un derecho, independientemente la naturaleza del acto generador del daño"19.

Dicha responsabilidad es excepcional en nuestro ordenamiento jurídico y se reconoce solamente en algunas leyes, como la Ley $N^{\circ} 18.302$, de daños producidos por accidentes nucleares, Decreto Ley № 2.222, sobre Derrames de Hidrocarburos y la Ley No 15.703, sobre los Perjuicios Causados por la Fumigación.

- Responsabilidad subjetiva, o la que es también conocida como la responsabilidad por falta de servicio, que no es otra cosa que la culpa del servicio, compatible con el contenido normativo del Código Civil. Doctrina defendida principalmente por el ministro de la Corte Suprema Pedro Pierry Arrau, y que es la que prevalece hoy en día en materia de responsabilidad estatal. Se consagra principalmente en la Ley Orgánica Constitucional de Municipalidades (Ley $\mathrm{N}^{0}$ 18.635), y en el artículo 42 de la Ley de Bases de la Administración del Estado ${ }^{20}$ (Ley No 18.575).

- Responsabilidad objetiva relativa, es una teoría mixta entre las dos anteriores. Es aquella que "considera la responsabilidad extracontractual del Estado requiere algún título de imputabilidad que objetivase los reproches a la Administración, pero al mismo tiempo da un valor limitado a la norma del artículo 38, inciso $2^{\mathrm{o} \prime 21}$.

$>$ Responsabilidad del Estado-Juez ${ }^{22}$.

Esta responsabilidad toma forma en el acto jurisdiccional o resolución judi$\mathrm{cia}^{23}$, en donde el juez incurre en un error grave, que se puede dar dentro del proceso o en el momento en que dicta sentencia, provocando perjuicios tanto patrimoniales, como en su honor al afectado.

Fruto de lo anterior, es necesario que el perjuicio que se produce por el error sea reparado.

Teniendo esta imagen general sobre la responsabilidad, y específicamente sobre la del Estado, se puede entender y abordar la responsabilidad del Ministerio Público como ente de la administración del Estado, por los errores cometidos en un proceso penal, en contraposición a la existente, pero ineficaz, responsabili-

\footnotetext{
${ }^{19}$ Cordero, Luis, La responsabilidad, cit. nota n. 13, pp. 48.

${ }^{20}$ Artículo 42 LGBAE.- Los órganos de la Administración serán responsables del daño que causen por falta de servicio. No obstante, el Estado tendrá derecho a repetir en contra del funcionario que hubiere incurrido en falta personal.

${ }^{21}$ Cordero, Luis, La responsabilidad, cit. nota n. 13, p. 66.

${ }^{22}$ García, Hernán, La responsabilidad, cit. nota n. 14, pp. 223-460.

${ }^{23}$ ZúNIIGA, Francisco, "La acción", cit. nota n. 10, p. 23.
} 
dad del Estado como juez consagrada en la acción de indemnización judicial (artículo 19, No 7 letra i) de la CPR).

\section{Responsabilidad por las actuaciones del Ministerio Público}

\subsection{Funciones y deberes \\ 2.1.1. Órgano constitucionalmente autónomo}

El Ministerio Público es un organismo que fue creado e introducido a la CPR por la Ley de reforma constitucional № 19.519 de septiembre del año 1997, y regulado por su LOC No 19.640 de octubre de 1999. Su creación obedeció a la reforma procesal penal, y principalmente a la idea de separación de funciones en el proceso entre la investigación y el juzgamiento del asunto.

Siguiendo la opinión del profesor Fernánde $z^{24}$, el Ministerio Público no solo goza de jerarquía constitucional por ser creado por la Constitución, sino que además ha sido dotado de autonomía, al igual que otros órganos como el Consejo Nacional de Televisión, la Contraloría General de la República, las Municipalidades y el Banco Central.

Lo que esto implica, es que los órganos constitucionalmente autónomos no forman parte del Gobierno (orgánica, procesal, ni funcionalmente), aunque se relacionan con él, existiendo una separación de funciones, con ciertas atribuciones que históricamente están vinculadas con el Gobierno o el Poder Judicial $^{25}$.

Así, se entiende que órganos autónomos como el Ministerio Público, no están clasificados dentro de la visión tradicionalista de los tres poderes del Estado (Ejecutivo, Legislativo y Judicial), y gozan de este atributo específicamente para no ser dependientes de alguna entidad u órgano correspondiente a alguno de estos tres poderes, como podría ser, por ejemplo, estar bajo el alero de la Corte Suprema, el Ministerio del Interior, el Ministerio de Justicia o el Congreso. Se puede entender esta autonomía de la siguiente manera:

"En fin, y respecto de los efectos, la autonomía supone un nivel-mayor o menor-de independencia de otros...; en el caso de los órganos constitucionalmente autónomos, se los dota de autonomía para excluirlos de los Órganos Constitucionales que desempeñan las funciones clásicas, esto, la función Gubernativa -con sus tres subfunciones, Política, Administrativa y Ejecutiva-, la Función Judicial y la Legislativa. Particularmente, en el caso del Gobierno, entendido éste en sentido estricto, el efecto de dotar de autonomía a un ente es excluirlo de la Administración Pública y del control que se ejerce sobre

${ }^{24}$ Fernández, Miguel Ángel, La Nueva Justicia Penal frente a la Constitución, Editorial LexisNexis, Santiago, 2006, p. 179.

${ }^{25}$ FernánDEZ, Miguel Ángel, La Nueva, cit. nota n. 24, p. 179. 
ella, sea que el examen se ejerza por la denominada Administración Pasiva o el que tiene carácter político" 26 .

No se debe entender como si estos órganos estuvieran fuera de la estructura que rige nuestro ordenamiento, por lo que no serían objeto de responsabilidad en el desempeño de sus funciones, sino que están sujetos a otro tipo de control y, al igual que cualquier órgano del Estado o particular, deberán responder por los daños que causen. Así, entonces, la implicancia de considerarlo un órgano autónomo no es otra que estructurar el Estado de hoy en día en torno a una visión moderna, dejando de lado la división clásica de tres Poderes, "agregando nuevas funciones como la contralora, la investigativa penal, la jurisdiccional en sede constitucional, la jurisdiccional en materia electoral, la monetaria, la de seguridad y la municipal"27.

Específicamente, en el caso del Ministerio Público, esta autonomía no debe entenderse de otra manera, sino de la que se extrae de su propia historia:

"Se entiende por autonomía la potestad para dirigirse a sí mismo sin intervención de terceros; ella tiene una dimensión funcional consistente en el libre y expedito cumplimiento de las funciones otorgadas, y una operativa, que permite hacer cumplir las decisiones adoptadas..."28.

Por lo tanto, es importante tener en cuenta a la hora de revisar su responsabilidad por errores injustificadamente erróneos o arbitrarios dentro del proceso penal, que la investigación se encuentra separada de la función jurisdiccional. Su responsabilidad se configura como el de ente autónomo constitucional, esto es, un órgano de la Administración del Estado, y que no forma parte del Poder Judicial.

\subsubsection{Funciones y principios}

Está definido en su misma LOCMP, en el artículo $1^{029}$, del cual se desprenden sus funciones generales ${ }^{30}$ :

\footnotetext{
${ }^{26}$ FeRnÁndeZ, Miguel Ángel, "Autonomía de los grupos intermedios y determinación de sus propios fines específicos", en XXX Jornadas Chilenas de Derecho Público, Valparaíso, Facultad de Derecho de la Universidad de Valparaíso, 1999, pp. 77 y ss., en Fernández, La Nueva, cit. nota n. 24, p. 182.

${ }^{27}$ Fernández, La Nueva, cit. nota n. 24, p. 186.

${ }^{28}$ Informe de la Comisión de Constitución, Legislación, Justicia y Reglamento del Senado, recaído en el proyecto de ley de reforma constitucional que crea el Ministerio Público, evacuado el 8 de abril de 1997, sesión 39a , p. 4565.

${ }^{29}$ Art. $1^{\circ}$ Ley No 19.640 .- El Ministerio Público es un organismo autónomo y jerarquizado, cuya función es dirigir en forma exclusiva la investigación de los hechos constitutivos de delito, los que determinen la participación punible y los que acrediten la inocencia del imputado y, en su caso, ejercer la acción penal pública en la forma prevista por la ley. De igual manera, le corresponderá la adopción de medidas para proteger a las víctimas y a los testigos. No podrá ejercer funciones jurisdiccionales.

${ }^{30}$ Horvitz, María Inés; LóPEZ, Julián, Derecho Procesal Penal Chileno, Santiago, Editorial Jurídica de Chile, 2002, t. I., pp. 143-149.
} 
>Dirigir exclusivamente la investigación de delitos, hechos que acreditan su comisión y la participación punible, como también los que extinguen su responsabilidad penal.

$>$ Ejercer, en su caso, la acción penal pública (lo que se traduce en efectuar la acusación).

Dar protección a las víctimas y testigos (de esta manera de busca evitar una situación de desamparo de estos sujetos en el sistema).

El Ministerio Público ejerce sus funciones por medio de los fiscales, que son aquellos que tienen el deber que llevar a cabo las funciones recién nombradas, y son ellos que no efectuando debidamente sus funciones pueden acarrear la responsabilidad y el deber de indemnizar por parte del Ministerio Público (independientemente de las responsabilidades funcionarias o de otro tipo por sus actuaciones).

De esta manera, tanto la LOCMP como la CPR establecen principios que deben orientar las funciones de este órgano, y específicamente del actuar de los fiscales ${ }^{31}$ :

- Objetividad (arts. $1^{\circ}$ y $3^{\circ}$ LOCMP): los fiscales deben adecuar sus actos a un criterio objetivo, velando únicamente por la correcta aplicación de la ley. Esto implica investigar con la misma diligencia tanto los hechos y circunstancias que funden o agraven la responsabilidad del imputado, como también, los que la eximan, extingan o atenúen.

Resulta discutible hoy en día la aplicación de este principio, ya que a los fiscales se les critica constantemente por no lograr altas penas o privación de libertad del imputado, pensándose popularmente (tanto por la gente de la calle, como por el mismo Poder Ejecutivo o el Congreso) que su única función es buscar la responsabilidad del imputado. Esto implica que su responsabilidad se puede configurar para ambos lados, es decir, en primer término, el no hacer con la debida diligencia o celo la labor de investigación del delito y buscar la responsabilidad e imputación del acusado; o en el sentido contrario, empecinarse a buscar la condena del imputado, cuando resulta que éste puede ser inocente.

- Oficialidad: no es otra cosa que el Estado tiene la atribución privativa de la acción penal pública. Las excepciones a este principio se dan en la acción penal pública previa instancia de particular, la acción penal privada, y ciertos delitos que exigen el cumplimiento de una condición objetiva de procesabilidad ${ }^{32}$.

- Legalidad: Una vez que los fiscales toman noticia de un hecho que reviste características de delito, tienen la obligación de investigar y acusar si es que corresponde.

\footnotetext{
${ }^{31}$ Horvitz y López, Derecho Procesal, cit. nota n. 30, pp. 149-163.

32 Horvitz y López, Derecho Procesal, cit. nota n. 30, p. 150.
} 
Aquí se manifiesta cómo los fiscales, haciendo mal uso de este principio, pueden llegar a dañar los derechos fundamentales de las personas en el proceso penal (como el principio de inocencia, privación de libertad, derecho a guardar silencio, derecho a no declarar contra familiares, etc.), lo que puede configurar el deber de responder por parte del Ministerio Público y, específicamente, del Estado-Fisco por los daños causados.

- Eficiencia (art. $6^{\circ}$ LOCMP): fiscales y funcionarios tienen la obligación de actuar de manera eficiente en la administración de los recursos y en el cumplimiento de sus funciones. Es decir, un deber, de actuar con rapidez y diligencia, ya que el tiempo puede llevar a ciertas cosas dañinas, como, por ejemplo, la destrucción de pruebas determinantes para imputar la responsabilidad de un acusado, o también una lenta investigación puede afectar a una persona privada de libertad.

- Transparencia y probidad (art. $8^{\circ}$ LOCMP): deben observar la probidad administrativa. Esto implica la publicidad de sus procedimientos y que fundamenten las decisiones que adopten.

Se puede apreciar cómo la transgresión de estos principios puede afectar los derechos de los particulares, por ejemplo, aquellas causas donde tengan un interés particular el fiscal que afecte su imparcialidad en el asunto, o que decretado el secreto (incluido en el principio de publicidad, que es la regla general, pero en base al inciso $4^{\circ}$ del art. $8^{\circ}$ se puede decretar secreto en ciertos casos ${ }^{33}$, se divulgue esa información (por ejemplo, la divulgación de una intervención telefónica que se autorizó durante el proceso) ${ }^{34}$.

- Responsabilidad: principio, en virtud del cual el Ministerio Público y los fiscales deben responder por sus actuaciones. Se tratará con profundidad más adelante.

Son estos los principios fundamentales a los cuales deben someter su actuar y respecto de los que se puede configurar su responsabilidad. Otros autores,

\footnotetext{
${ }^{33}$ Artículo $8^{\circ}$ inciso $4^{\circ}$ LOCMP.- Son públicos los actos administrativos del Ministerio Público y los documentos que les sirvan de sustento o complemento directo y esencial. Con todo, se podrá denegar la entrega de documentos o antecedentes requeridos en virtud de las siguientes causales: la reserva o secreto establecidos en disposiciones legales o reglamentarias; cuando la publicidad impida o entorpezca el debido cumplimiento de las funciones del organismo; la oposición deducida por terceros a quienes se refiera o afecte la información contenida en los documentos requeridos; el que la divulgación o entrega de los documentos o antecedentes requeridos afecte sensiblemente los derechos o intereses de terceras personas, según calificación fundada efectuada por el respectivo Fiscal Regional o, en su caso, el Fiscal Nacional, y el que la publicidad afecte la seguridad de la Nación o el interés nacional. El costo del material empleado para entregar la información será siempre de cargo del requirente, salvo las excepciones legales.

${ }^{34}$ Ortega Monsalva, Pablo con Consejo de Defensa del Estado, Corte Suprema, 12 de julio de 2011, Rol № 2765-2009, Microjuris, MJJ28476.
} 
como Otero Lathrop ${ }^{35}$ agregan principios a los que deben someterse: agilidad en el actuar; control jerárquico; fácil acceso de los particulares a los fiscales: igualdad de condiciones para postular a sus cargos.

\subsection{Responsabilidad por sus actuaciones}

Como se dijo anteriormente, uno de los principios a los que está sometido el Ministerio Público, y específicamente los fiscales que realizan su labor, es el principio de responsabilidad, cuya definición y alcance ya se explicaron en el apartado primero de este trabajo.

Para poder entender cabalmente este principio, en primer lugar, hay que distinguir entre la responsabilidad de los fiscales en el ejercicios de sus funciones y la responsabilidad del Ministerio Público por las actuaciones de los fiscales.

Respecto de los primeros, se regulan en el artículo $45^{36}$ y siguientes de la LOCMP, y se pueden distinguir las siguientes responsabilidades ${ }^{37}$ :

$>$ Responsabilidad civil.

Responsabilidad penal, que a su vez se puede dividir en:

- Responsabilidad penal general.

- Responsabilidad por delitos ministeriales.

$>$ Responsabilidad disciplinaria-administrativa, que se puede distinguir entre:

- Responsabilidad por la no declaración oportuna de intereses.

- Responsabilidad disciplinaria propiamente tal.

Por su parte, la segunda, (responsabilidad del Ministerio Público por las actuaciones de los fiscales), y objeto del presente trabajo, se encuentra regulada en el art. $5^{\circ}$ de la LOCMP:

"El Estado será responsable por las conductas injustificadamente erróneas o arbitrarias del Ministerio Público.

La acción para perseguir esta responsabilidad patrimonial prescribirá en cuatro años, contados desde la fecha de la actuación dañina.

En todo caso, no obstará a la responsabilidad que pudiese afectar al fiscal o funcionario que produjo el daño, y, cuando haya mediado culpa grave o dolo de su parte, al derecho del Estado para repetir en su contra".

A través de esta fórmula, lo que se busca es obtener la reparación por parte del Estado (Fisco) por errores injustificadamente erróneos o arbitrarios que

\footnotetext{
${ }^{35}$ Otero, Miguel, El Ministerio Público, reforma constitucional y ley orgánica constitucional, Editorial LexisNexis, Santiago, 2002, pp. 78-86.

${ }^{36}$ Artículo 45 LOCMP.- Los fiscales del Ministerio Público tendrán responsabilidad civil, disciplinaria y penal por los actos realizados en el ejercicio de sus funciones, de conformidad a la ley.

${ }^{37}$ Horvitz y López, Derecho Procesal, cit. nota n. 30, pp. 160-163; y Otero, El Ministerio Público, cit. nota n. 35, pp. 115-124.
} 
cometa el Ministerio Público (los fiscales en el ejercicio de sus funciones). Desligándose esta acción de la contemplada en el art. $19 \mathrm{~N}^{\circ} 7$ letra i) de la CPR ("acción de indemnización por error judicial"), configurándose dos tipos de responsabilidades distintas: por una parte, como se dijo anteriormente, el Ministerio Público es un órgano autónomo, que no pertenece al Poder Judicial, por lo que se configura en su caso una responsabilidad por parte de un ente de la Administración del Estado, y no una responsabilidad Estado-Juez.

Así se desprende del segundo informe de la Comisión Técnica del Senado, de la discusión del proyecto de LOCMP ${ }^{38}$ :

"Coincidió la Comisión en que la trascendencia de las funciones que la Carta Fundamental encomienda al Ministerio Público y la posibilidad que ella contempla en cuanto a que, en el desempeño de su actividad, realice actos que priven, restrinjan o perturben el ejercicio de derechos fundamentales, aunque para ello se requiera autorización judicial previa, hace indispensable regular la responsabilidad correlativa y no dejar entregada esta materia de discusión doctrinaria y a la decisiones judiciales, necesariamente casuística, como única forma de crear seguridad jurídica".

La tramitación y explicación de esta norma se realizará detalladamente en el próximo apartado, sin embargo, adelanto la discusión y temor de algunos autores de que el concepto injustificadamente errónea o arbitraria a que hace mención esta ley se interprete de la misma manera que como la ha venido haciendo la Corte Suprema para el caso de acción de indemnización por error judicial ${ }^{39}$. Sin embargo, de la historia fidedigna de su establecimiento, se puede apreciar que el constituyente quiso darle mayor amplitud a esta norma, y no encerrarla en relación a la acción constitucional ${ }^{40}$.

"Con todo, siendo esta materia de iniciativa exclusiva de S.E. el Presidente de la República, el Primer Mandatario formuló la indicación número 1, para consignar que el Estado será responsable por los actos injustificadamente erróneos o arbitrarios del Ministerio Público.

La Comisión aceptó este criterio, que guarda concordancia con la responsabilidad del Estado por su actividad jurisdiccional, la cual procede, respecto de aquella resolución que se 'injustificadamente errónea o arbitraria', sin perjuicio de que esta última constitucionalmente restringida a los casos que hayan redundado en el sometimiento a proceso o condena del afectado. No obstante, le preocupó que, al mencionar los actos, queden excluidas las omisiones en que incurra el Ministerio Público. Por tal motivo, optó por hacer referencia a 'las conductas' en el entendido de que, de esa forma, se está comprendiendo tanto las acciones como las omisiones de este organismo".

\footnotetext{
${ }^{38}$ Otero, El Ministerio Público, cit. nota n. 35, p. 87.

${ }^{39}$ Horvitz y López, Derecho Procesal, cit. nota n. 30, pp. 162-163; Duce, Mauricio; RieGo, Cristian, Procesal Penal, Editorial Jurídica, Santiago, 2007, p. 559; FernÁndez, La Nueva, cit. nota n. 24, pp. 269271.

${ }^{40}$ Otero, El Ministerio Público, cit. nota n. 35, pp. 87-88.
} 
Se puede concluir, en primer lugar, que pese a que esta norma de responsabilidad, y específicamente el concepto de "injustificadamente errónea o arbitraria", tiene su origen en la norma constitucional, no se aplican a los mismos casos. Y, en segundo lugar, que se entienden incluidas tanto las acciones como las omisiones del Ministerio Público.

\subsection{El Ministerio Público como órgano de la administración del Estado}

Un aspecto importante a determinar es la característica del Ministerio Público como un órgano que forma parte de la administración del Estado, de tal manera que al analizar su responsabilidad por las conductas erróneas o arbitrarias de los fiscales se esté hablando efectivamente de una responsabilidad estatal.

Conforme al artículo 83 de la Constitución Política de la República el Ministerio Público es "un organismo autónomo y jerarquizado", por lo tanto, conforme a lo explicado por el profesor Cordero ${ }^{41}$ se trata de órganos que integran la administración del Estado, distinguiéndose de aquellos órganos que forman parte del Poder Judicial o Legislativo.

El carácter autónomo, ya explicado en el primer subtítulo de este capítulo, en palabras de Cordero "dice relación con las facultades que tiene el Presidente de la República en relación a determinados órganos que integran la administración del Estado, respecto de los cuales no existe un vínculo de jerarquía y los mecanismos de tutela o supervigilancia son bastante atenuados"42. Es así como podemos clasificarlo dentro de los organismos constitucionalmente autónomos, es decir, aquellos que la propia Constitución les da autonomía con respecto al Presidente de la República. Y tal como se desprende de los artículos 28 y 29 de la Ley de Bases de la Administración del Estado (LOC No 18.675) es un servicio público funcionalmente descentralizado, por lo que tiene una personalidad jurídica propia, un patrimonio propio (lo que no quiere decir que no esté incluido dentro de la ley de presupuesto) y se encuentra bajo la supervigilancia del Jefe de Estado.

Asimismo, es la propia Contraloría General de la República la que se ha encargado de sostener que estos órganos forman parte de la administración del Estado:

"el ordenamiento constitucional y legal señalan claramente lo que debe entenderse por Administración estatal o Administración pública, la que comprende de modo amplio, a todos los órganos y servicios públicos creados para cumplir la función admi-

${ }^{41}$ Cordero, Eduardo, "La administración del Estado en Chile y el concepto de autonomía", Contraloría General de la República 85 años de vida, Santiago, 2012, pp. 16-17.

${ }^{42}$ Cordero, cit. nota n. 41, p. 21. 
nistrativa del Estado, incluidos aquellos establecidos por la Carta Fundamental como autónomos" ${ }^{\prime 4}$.

Con respecto a que se trata de un órgano jerarquizado, dicha característica denota la idea de la existencia de una estructura compuesta por un Fiscal Nacional, seguido por Fiscales Regionales y más abajo Fiscales Adjuntos ${ }^{44}$.

De lo dicho anteriormente no cabe duda que el Ministerio Público forma parte de la administración del Estado y no del Poder Judicial o Legislativo, por lo tanto es perfectamente posible, como ya se ha dicho, que se configure una responsabilidad estatal por sus actuaciones.

\section{RESPONSABILIDAD POR ERROR JUDICIAL}

\subsection{Acción de indemnización por error judicial}

Esta acción se encuentra regulada en nuestro ordenamiento jurídico en el art. $19 \mathrm{~N}^{\circ} 7$ letra i) de la Carta Magna:

"Una vez dictado sobreseimiento definitivo o sentencia absolutoria, el que hubiere sido sometido a proceso o condenado en cualquier instancia por resolución que la Corte Suprema declare injustificadamente errónea o arbitraria, tendrá derecho a ser indemnizado por el Estado de los perjuicios patrimoniales o morales que haya sufrido. La indemnización será determinada judicialmente en un procedimiento breve y sumario y en él la prueba se apreciará en conciencia".

De su lectura se puede establecer que las bases para hacer posible la indemnización son las siguientes ${ }^{45}$ :

$>$ Toda persona que fue procesada (sometida a proceso) o condenada en cualquier instancia, y de quien se dictó sobreseimiento definitivo o sentencia absolutoria.

$>$ Que dicha resolución o sentencia debe ser declarada injustificadamente errónea o arbitraria por la Corte Suprema.

Como se dijo en el principio de esta obra, dicha acción no ha cumplido con su objetivo de indemnizar a las personas afectadas, por lo tanto, se ha generado un espacio en nuestro ordenamiento jurídico de irresponsabilidad del Estado, es decir, el Estado no responde por los errores injustificadamente erróneos o arbitrarios que cometa un juez durante un proceso penal.

La razón de lo anterior deriva de la interpretación y aplicación de tres elementos fundamentales de dicha norma. Estos son:

\footnotetext{
${ }^{43}$ Cordero, cit. nota n. 41, p. 30.

${ }^{44}$ Cea Egaña, José Luis, "Fisonomía Constitucional del Ministerio Público de Chile", Revista de Derecho Valdivia, Universidad Austral, vol. 10 supl., 1999, pp. 59-66.

45 Mouina, Hernán, Derecho Constitucional, $8^{a}$ ed., Editorial LexisNexis, Santiago, 2008, pp. 214215.
} 
Sometido a proceso o condenado en cualquier instancia ${ }^{46}$;

Sobreseído definitivamente o se haya dictado sentencia absolutoria a su favor $^{47}$;

Que la Corte Suprema declare que dichas resoluciones son injustificadamente erróneas o arbitrarias ${ }^{48}$.

\subsubsection{Causas jurídicas y prácticas de la ineficacia de la acción}

Como se ha establecido anteriormente, son tres los elementos que generan el problema a la hora de buscar la responsabilidad del Estado por los daños causados en el ejercicio de la actividad judicial. Pasaremos a examinar cada uno de ellos.

\section{a) Sometido a proceso o condenado en cualquier instancia}

En primer lugar, se debe distinguir entre las expresiones sometido a proceso y condenado en cualquier instancia. Con respecto a esta segunda no existen mayores problemas, ya que dice relación con aquella persona que ha sido declarada culpable de cualquier delito y que signifique una privación de libertad.

En cambio, sometido a proceso constituye uno de los mayores obstáculos a que dicha acción pueda satisfacer su ideal. La razón de aquello es que sometido a proceso dice relación con una resolución que se consagraba en el antiguo artículo 274 del Código de Procedimiento Penal ${ }^{49}$, que era conocida como la encargatoria de reo ${ }^{50}$, y en virtud de la cual se le exigía al juez que constare dos circunstancias: a) que esté justificada la existencia del delito y b) que hayan presunciones fundadas de que el inculpado ha tenido participación en el delito como autor, cómplice o encubridor ${ }^{51}$. Con la entrada en vigencia del Código Procesal Penal el año 2000, esta resolución desapareció, ya que atentaba en

\footnotetext{
${ }^{46}$ Garrido Montt, Mario, "La indemnización por error judicial en Chile", lus et Praxis, 1999, vol.5, pp. 476-477; y FernándeZ, La Nueva, cit. nota n. 25, pp. 243-265.

${ }^{47}$ GarRIDO, "La indemnización", cit. nota n. 46, pp. 477-479.

${ }^{48}$ Garrido, "La indemnización", cit. nota n. 46, pp. 476-477; Precht Pizarro, Jorge, "Resolución injustificadamente errónea o arbitraria en la indemnización por error judicial", Estudios Constitucionales, 2004, vol. 2, número 001, pp. 175-180.

${ }^{49}$ C.P.P. Artículo 274.- Después que el juez haya interrogado al inculpado, lo someterá a proceso, si de los antecedentes resultare: $1^{\circ}$ Que está justificada la existencia del delito que se investiga, $2^{\circ}$ Que aparecen presunciones fundadas para estimar que el inculpado ha tenido participación en el delito como autor, cómplice o encubridor. El juez procesará al inculpado por cada uno de los hechos punibles que se le imputen, cuando concurran las circunstancias señaladas.

${ }^{50}$ GARRIDO, "La indemnización", cit. nota n. 46, p. 476.

${ }^{51}$ Garrido, "La indemnización", cit. nota n. 46, p. 477.
} 
contra del Principio de Inocencia regulado en el artículo 4 del mismo Código ${ }^{52}$. Esto ha ocasionado un efecto no contemplado con la entrada en vigencia del nuevo proceso penal, ya que se afectó una norma constitucional que busca reparar patrimonial y moralmente a aquellas personas que han sido injustamente privadas de libertad. Entonces la pregunta que hay que hacerse con base en la normativa vigente es ¿qué debe entenderse por sometido a proceso? Hay autore $^{53}$ que plantean que sin perjuicio de una necesaria modificación en la Constitución, y a la luz de la normativa vigente, dicha frase se debe entender para los casos en que las personas hayan sido sometidas a prisión preventiva y hayan sido formalizados por el Ministerio Público ${ }^{54}$.

Fruto de lo anterior, y mientras no exista una reforma constitucional al precepto invocado, es que "sometido a proceso", va a seguir significando un obstáculo para el ejercicio de esta norma, ya que actualmente queda abierto a la interpretación de la Corte Suprema el sentido que deba darse a ésta.

\section{b) Sobreseído definitivamente o se haya dictado sentencia absolutoria a su favor}

El segundo requisito que se exige para que proceda la indemnización es que se haya dictado sobreseimiento definitivo o sentencia absolutoria respecto del que ha sido sometido a proceso o condenado.

Respecto del primer elemento, el sobreseimiento definitivo ${ }^{55}$, éste se regula en los artículos 248 y siguientes del Código Procesal Penal. En estos se distinguen dos tipos: el sobreseimiento definitivo y el sobreseimiento parcial (art. 252 CPP), no pudiendo solicitar la indemnización cuando se trata de este segundo. Esto por una interpretación restrictiva del precepto y no debiendo extenderla a puntos no contemplados. También se distingue entre sobreseimiento total o parcial, si se refiere a todos los delitos y a todos los imputados en el primer caso, o si se refiere sólo a algún delito o a algún imputado. Dicha distinción no tiene mayor relevancia para la aplicación del precepto en discusión.

El sobreseimiento definitivo es dictado por el juez de garantía en ciertos ca$\operatorname{sos}^{56}$, pero es un listado que permite varias hipótesis, de tal manera que la Corte

\footnotetext{
${ }^{52}$ Código Procesal Penal. Art. $4^{\circ}$.- Presunción de inocencia del imputado. Ninguna persona será tratada como culpable ni tratada como tal en tanto no fuere condenado por una sentencia firme.

${ }^{53}$ Garrido, "La indemnización", cit. nota n. 46, p. 477; y Fernández, La Nueva, cit. nota n. 25, pp. 243265.

${ }^{54}$ Horvitz y López, Derecho Procesal, cit. nota n. 30, pp. 417-418.

${ }^{55}$ Horvitz y López, Derecho Procesal, cit. nota n. 30, pp. 580-583.

${ }^{56}$ Código Procesal Penal. Art. 250; y Horvitz y LóPeZ, Derecho Procesal, cit. nota n. 30, t. I. p. 580. "El juez de garantía decretará el sobreseimiento definitivo, en la audiencia convocada al efecto, en los siguientes casos: a) Cuando el hecho investigado no sea constitutivo de delito; b) Cuando aparezca
} 
Suprema ha establecido que para que proceda la indemnización es necesario que se declare inocente al afectado, lo que ha llevado a la Corte a rechazar la solicitud de indemnización en muchas ocasiones, ya que sin perjuicio de dictarse sobreseimiento definitivo o sentencia absolutoria la inocencia del afectado no queda acreditada ${ }^{57}$ (como puede suceder con un indulto; perdón del ofendido; muerte del responsable, ya que a diferencia de otros países en Chile no se reconoce el derecho de los familiares a obtener una indemnización ${ }^{58}$; etc.).

Respecto de la segunda condición que puede darse, esta es, la dictación de una sentencia absolutoria, que puede presentarse tanto en primera instancia (luego que ha sido sometido a prisión preventiva), como en segunda instancia (sentencia que revoque la sentencia que lo privo de libertad en primera instancia), no reviste ningún problema a la hora de su aplicación.

\section{c) Resolución injustificadamente errónea o arbitraria}

El artículo 19 № 7 letra i) de la CPR establece "...por resolución que la Corte Suprema declare injustificadamente errónea o arbitraria...".

De esta frase se desprende que es necesaria una resolución de la Corte Suprema que declare que el actuar del juez ha sido injustificadamente erróneo o en otro caso que este actuar ha sido arbitrario. Dicha expresión, según la doctrina mayoritaria, ha sido el mayor obstáculo para que la acción en cuestión tenga la eficacia necesaria y se repare el daño a los afectados.

En opinión de Carocca $^{59}$, dichos elementos se incluyeron con el objetivo de que se debían acreditar ciertas circunstancias para que procediera la indemnización, y así evitar una proliferación del deber del Estado de responder; el problema es que dichos supuestos no sólo llevaron a evitar esto, sino que se llegó al otro extremo: no concederlo casi nunca.

En la doctrina tampoco existe consenso acerca de lo que se debe entender por error y por arbitraria. Garrido Montt ${ }^{60}$ sostiene que incurre en error "aquel

claramente establecida la inocencia del imputado; c) Cuando el imputado se encuentre exento de responsabilidad criminal en conformidad al artículo10 del Código Penal o en virtud de otra disposición leal; d) Cuando se haya extinguido la responsabilidad penal del imputado por alguno de los motivos establecidos en la ley (art. 95 Código Penal); e) Cuando sobrevenga un hecho, que con arreglo a la ley, ponga fin a dicha responsabilidad, y f) Cuando el hecho de que se trate haya sido materia de un procedimiento penal en el que haya recaído sentencia firme respecto del imputado.

${ }^{57}$ García, La responsabilidad, cit. nota n. 14, pp. 280-460.

${ }^{58}$ AgüERo, Mirta Noemí, Responsabilidad del Estado y de los Magistrados por Error Judicial, Editorial Ad-Hoc, Buenos Aires, 1995, p. 31.

${ }^{59}$ CAROCCA, Alex, "Reflexiones sobre el derecho a la reparación por error judicial en Chile a propósito de la solución amistosa ante la Comisión Interamericana de Derechos Humanos en el Ilamado caso La Calchona", Ius et praxis, 2002, pp. 641-660.

${ }^{60}$ GarRIDO, "La indemnización", cit. nota n. 46, p. 477. 
que tiene un equivocado concepto de la verdad o de la realidad. Cuando la sentencia se ha sustentado en una mala apreciación de la realidad, este yerro puede ser fundamento de la declaración que ha de hacer el Tribunal Supremo", y por arbitraria entendemos cuando la resolución "es sin razón, absolutamente improcedente, defecto que da lugar a la declaración sobre el derecho al pago de una indemnización" ${ }^{\prime \prime 6}$. Junto con lo anterior estima que injustificadamente se aplica tanto a errónea como arbitraria, de manera tal que "tiene que cometerse un error inexcusable, inaceptable...".

Por otro lado, Precht Pizarro ${ }^{62}$ sostiene que no se puede entender del texto que injustificadamente se aplica también arbitraria, estableciendo que "no puede haber arbitrariedades justificadas o parcialmente justificadas en un Estado de Derecho, y en consecuencia no cabe duda que injustificadamente solo puede predecirse del error". Así es como la mayoría de la doctrina entiende dicho concepto, y es como se ha aplicado.

Se denota la interpretación excesivamente restrictiva que le ha dado la Corte Suprema a esta norma y, por consiguiente, su difícil aplicación, en las sentencias dictadas por el Máximo Tribunal el 11 y 19 de agosto de 1989 (Gaceta Jurídica No 110, pp. 54-63), que según Pereira Anabalón ${ }^{63}$ "declararon que para que una resolución tenga el carácter de errónea o de arbitraria en grado de injustificable, es necesario que además de ser contradictoria con la razón se haya decretado de manera irregular o caprichosa". Es decir, se ha establecido un estándar prácticamente imposible.

Frente a la dificultad de interpretación de esta norma, lo recomendable es recurrir, conforme al art. 19 del Código Civil, a la historia fidedigna de su establecimiento, pero de su lectura nos podemos dar cuenta que en los intentos por lograr delimitarla finalmente se llega a una mayor confusión ${ }^{64}$. A modo de ejemplo, las palabras de Enrique Evans en la sesión 119ª de la "Comisión Ortúzar":

"¿En qué casos es injustificado el error, se pregunta el comisionado Enrique Evans, de relevante participación en la gestación del precepto? Y se responde: 'Cuando no hay elementos que intelectualmente a una mente normal puedan haberla llevado a la conclusión que llegó el juez'. Y agrega a continuación: 'Esa es arbitrariedad"'"65.

\footnotetext{
${ }^{61}$ Corte Suprema, 20 de mayo de 1998, Rol № 216-1998.

${ }^{62}$ Precht, "Resolución injustificadamente", cit. nota n. 47, vol. 2, p. 177.

${ }^{63}$ Pereira Anabalón, Hugo, "La responsabilidad del Estado por error judicial", Gaceta Jurídica № 275, 2003, p. 10.

${ }^{64}$ García, La responsabilidad, cit. nota n. 14, pp. 227-242; Sesiones 117 a 124 de la "Comisión Ortuzar" celebradas en 1975.

${ }^{65}$ Hernández, "Error judicial", cit. nota n. 2, pp. 468.
} 
Sin perjuicio de la discusión acerca de qué debe entenderse por error y por arbitrariedad ${ }^{166}$, el mayor problema ha venido por parte de la Corte Suprema que ha interpretado esta disposición de tal manera, que ha establecido como exigencia para proceder a ella que los requisitos injustificadamente erróneo y arbitraria deben darse copulativamente de manera de que la disposición debe entenderse: "...por resolución que la Corte Suprema declare injustificadamente errónea y arbitraria...", interpretando más allá de lo que establece la propia Constitución. Debido a esta interpretación es que la Corte Suprema ha rechazado múltiples de acciones destinadas a obtener indemnización por error judicial ${ }^{67}$.

Fruto de lo anterior, y al constatar las dificultades para la aplicación de esta norma, se piensa que realmente el legislador no quiso establecer un régimen de responsabilidad jurisdiccional, y así compartimos las palabras de Garrido Montt ${ }^{68}$ cuando dice:

"La referida excepcionalidad ha provocado cierta desilusión en los justiciables, por cuanto aspiran -como es natural- a que todo error o acto arbitrario sea causa suficiente para reclamar la reparación de los daños que el afectado ha sufrido. Esta idea no parece haber estado en la mente del constituyente, que consideró que era inconveniente debilitar la facultad persecutoria de los órganos represivos del Estado, ante el temor de que si fracasan aquél tendría que pagar una indemnización. Sería útil, repensar la norma con miras a ampliar la posibilidad de beneficio reparatorio".

Hace más de 12 años que se escribió lo recién citado, y hasta el día de hoy la norma constitucional sigue teniendo la misma aplicación: prácticamente nula.

\subsubsection{Jurisprudencia}

La tesis recién planteada se apoya en la jurisprudencia de la Corte Suprema, ya que desde su modificación en el año 1980 hasta la actualidad, sólo ha sido acogida en cuatro ocasiones:

- "Salinas Gómez con Fisco"69.

\footnotetext{
${ }^{66}$ PRECHT, "Resolución injustificadamente", cit. nota n. 47, p. 178. "Arbitrariedad es un acto o proceder contrario a la justicia, a la razón o a las leyes, dictado solo por la voluntad o el arbitrio (Diccionario de la RAE). El 'arbitrium' equivale al 'albedrío' y en el ámbito jurídico quiere significar la facultad que se concede por ley al juzgador (al juez o al tribunal) para poder decidir y apreciar la cuestión fundamental o meramente accidental y de trámite, según su criterio, según su libre albedrió o su propia conciencia". Y "el error es una equivocación, una mala apreciación ya sea de los hechos, sea del derecho, un concepto equivocado, un juicios falso".

${ }^{67}$ García, La responsabilidad, cit. nota n. 14, pp. 280-460.

${ }^{68}$ GARRIDO, "La indemnización", cit. nota n. 46, p. 478.

${ }^{69}$ Salinas Gómez con Fisco, Corte Suprema, 14 de noviembre de 1985, Rol № 24.518, Gaceta Jurídica № 65, 1985, pp. 71-74, y García, La responsabilidad, cit. nota n. 14, t. I, pp. 258-263.
} 
- "Araya Molina, Eugenio con Fisco"70.

- "Vega Rojas, Jorge del Carmen con Fisco"71.

- "Yáñez Pavez, María con Fisco"72.

Y también es menester nombrar el caso en donde se manifiesta más claramente la dificultad de aplicación de esta norma. Es el denominado caso "La Calchona"73, en donde se tuvo que Ilegar hasta la Corte I.D.H. para poder obtener el legítimo derecho a la reparación ${ }^{74}$.

Frente a la irresponsabilidad del Estado en esta materia, se encuentra como una solución parcial -me refiero así, ya que solo procederá en ciertos casosla acción por errores injustificadamente erróneos o arbitrarios el Ministerio Público.

\subsubsection{Tramitación}

Con el objeto de una posterior comparación con la acción contemplada en el art. $5^{\circ}$ de la LOCMP, la tramitación de la acción de indemnización por error judicial, regulado en un Autoacordado dictado por la Corte Suprema el 10 de abril de 1996, es la siguiente ${ }^{75}$ :

- Se presenta ante la Corte Suprema.

- Hay un plazo de 6 meses, que se cuenta desde que quede ejecutoriada la sentencia absolutoria o el sobreseimiento.

- Es obligatorio que venga patrocinado por abogado habilitado.

- Es necesario acompañar copia autorizada o certificado emitido por el tribunal de la sentencia absolutoria o el sobreseimiento definitivo.

- Se hace un estudio de admisibilidad respecto de los elementos recién vistos.

- Se dirige la acción en contra del Fisco (representado por el Consejo de Defensa del Estado).

- Se confiere traslado al Fisco por un término de 20 días.

\footnotetext{
${ }^{70}$ Araya Molina, Eugenio, Corte Suprema, 25 de julio de 1989, Rol № 23.833, Revista de Derecho y Jurisprudencia, Tomo 86, 1989, $2^{\text {a }}$ parte, sección 5a , pp. 85-91, y GARCíA, La responsabilidad, cit. nota n. 14 , t. I, pp. 264-271.

${ }^{71}$ Vegas Rojas, Jorge del Carmen, Corte Suprema, 5 de diciembre de 1990, Rol №27.662, Revista de Derecho y Jurisprudencia, Tomo LXXXVII, mayo-agosto de 1990, sección 5ª $2^{\text {a }}$ parte, pp. 184-189, y en García, La responsabilidad, cit. nota n. 14, pp. 271-280.

72 Yáñez Pavez María, Corte Suprema, 11 de agosto de 2011, Rol № 5411-2010.

${ }^{73}$ Corte Suprema, 27 de junio de 1996, Rol № 258.440.

${ }^{74}$ Carocca, "Reflexiones", cit. nota n. 59, pp. 641-660, y en Pereira, "La responsabilidad", cit. nota n. 63, pp. 11-12.

${ }^{75}$ Garrido, "La indemnización", cit. nota n. 46, pp. 479-480, y Molina, Derecho Constitucional, cit. nota n. 45, pp. 215-216.
} 
- Luego de los 20 días, con o sin respuesta, se enviarán los antecedentes al Fiscal Judicial.

- Luego se ordena dar cuenta de la presentación a la Sala Penal de la Corte Suprema (actualmente la $2^{\mathrm{a}}$ ), lo que se deberá hacer dentro de los 15 días siguientes, y ésta puede estimar oír los alegatos de las partes, que en dicho caso se agregará preferentemente a la tabla ordinaria de dicha Sala.

- Si la Corte dicta sentencia favorable, el monto de la indemnización lo determinará un Juzgado Civil a través de un procedimiento breve y sumario.

- La responsabilidad que se puede buscar frente al Fisco es tanto la patrimonial como la moral.

\subsection{Responsabilidad del Ministerio \\ Público por el error injustificadamente erróneo o arbitrario}

Como ya se ha dicho, el art. $5^{\circ}$ de la LOCMP establece una acción de responsabilidad estatal por las conductas del Ministerio Público:

“El Estado será responsable por las conductas injustificadamente erróneas o arbitrarias del Ministerio Público.

La acción para perseguir esta responsabilidad patrimonial prescribirá en cuatro años, contados desde la fecha de la actuación dañina.

En todo caso, no obstará a la responsabilidad que pudiese afectar al fiscal o funcionario que produjo el daño, y, cuando haya mediado culpa grave o dolo de su parte, al derecho del Estado para repetir en su contra".

En otras palabras, lo que se regula es el deber de responsabilidad del Estado derivado de las conductas injustificadamente erróneas o arbitrarias que cometan los fiscales en un proceso penal. No se debe confundir eso con la función jurisdiccional que ejerce el tribunal, ya que los fiscales no ejercen estas funciones. Este tipo de responsabilidad se podría configurar en ciertos casos, como por ejemplo $^{76}$ : al calificar la aplicación del Principio de Oportunidad (art. 170 del Código Procesal Penal); al resolver acerca de la autodenuncia (art. 179); al disponer la práctica de las diligencias contempladas en el art. 181, especialmente en su inciso $2^{\circ}$, las que establece el art. 197, o al formalizar la actuación, de acuerdo al art. 259.

Reafirma lo anterior el profesor Vodanovic ${ }^{77}$ :

"Los fiscales no ejercen actividad y carecen de potestad jurisdiccional, base sobre la que está considerada su responsabilidad. Por ello es que no les resulta aplicable la norma del $19 \mathrm{~N}^{\circ} 7$ letra i) ... Distinto será lo concerniente al daño producido por la actuación del Ministerio Público, o de la judicial promovida por él. Como anticipábamos, de la

\footnotetext{
${ }^{76}$ FERNÁNDEZ, La Nueva, cit. nota n. 24, p. 268.

${ }^{77}$ Vodanovic, "Comentario", cit. nota n. 6, p. 1.
} 
actuación del Ministerio Público, tanto de la investigación como especialmente del sostenimiento privativo de la acción penal, se derivan actos, hechos y situaciones procesales, como la privación cautelar de la libertad personal".

Esta norma no deroga la acción contemplada en la Constitución, pero sí reafirma el deber de responsabilidad del Estado de reparar los daños causados a las víctimas. Así se establece en el segundo informe de la Comisión Técnica del Senado ${ }^{78}$ : "Uno de los principios ya aceptados por la doctrina y la jurisprudencia es que el Estado debe responder por el daño que cause a las personas con su actividad u omisión, en su caso".

El precepto en estudio incorpora un nuevo autor del agravio, ya que antes de su entrada en vigencia, éste sólo podía ser cometido por el juez, precisándose que esta acción es una aplicación del precepto constitucional, pero aplicado al Ministerio Público, y con tramitación distinta. Este último elemento es de vital importancia, ya que no se está dejando la aplicación de ésta al arbitrio de la Corte Suprema.

"En efecto, la norma constitucional, sólo hacía concebible que el autor del agravio fuera el Juez. Empero y atendida la configuración del Nuevo Enjuiciamiento Criminal, donde las facultades investigativas quedan separadas de las vinculadas con el juzgamiento, no puede menos que concebirse la aplicación del precepto contenido en el artículo 19 № 7 letra i) tanto a las actuaciones del Tribunal tanto a las del Ministerio Público"779.

Algunos temores con respecto a esta norma ${ }^{80}$ son que va a suceder lo mismo que ocurre con la acción constitucional, es decir, el término injustificadamente erróneo o arbitrario se va a interpretar de la misma forma que ha llevado al imperio de la irresponsabilidad del Estado en este asunto.

Dichos temores, del todo fundados, no son ciertos ya que hay una diferencia fundamental, que se demostrará en el siguiente capítulo con la jurisprudencia de estos casos, que dice relación con que dichas acciones se tramitan de forma distinta y la conocen tribunales distintos. A primera vista no parece fundamental, pero en su aplicación las diferencias salen a la vista, sobre todo en su aplicación y efectividad de obtener la reparación por parte de las víctimas.

Un último tema a tratar dice relación con lo ya dicho anteriormente, que estamos en presencia de una acción diferente a la del art. $19 \mathrm{~N}^{\circ} 7$ letra i) de la CPR, pero que sí tiene una estricta relación con ésta. Debido a ello es que la responsabilidad del Ministerio Público puede reemplazar a la acción constitucional, pero en ciertas ocasiones, cuando la línea entre el actuar jurisdiccional

\footnotetext{
${ }^{78}$ Otero, El Ministerio Público, cit. nota n. 35, p. 87.

79 Fernández, La Nueva, cit. nota n. 24, p. 267.

${ }^{80}$ Horvitz y López, Derecho Procesal, cit. nota n. 30, pp. 162-163; Duce y RieGo, Procesal Penal, cit. nota n. 39 , p. 559.
} 
y el actuar del fiscal sea muy tenue, lo que se deberá considerar y probar caso a caso.

En resumen, y en concordancia con el profesor Vodanovic ${ }^{81}$, podemos afirmar que existen dos regímenes sobre la responsabilidad del Estado (enmarcados en este tema):

$>$ Daños causados por resoluciones judiciales manifiestamente erróneas o injustificadas.

Daños causados de conductas injustificadamente erróneas o arbitrarias del Ministerio Público.

\subsubsection{Cuestiones generales sobre la responsabilidad del Estado por las actuaciones del Ministerio Público}

Antes de seguir adelante con el estudio de la jurisprudencia de este asunto, hay que establecer algunas características propias de esta acción:

- Se tramitará como cualquier acción de responsabilidad estatal ante el Juzgado civil competente.

- No existe la responsabilidad objetiva. Supone necesariamente una actuación dolosa o negligente del Ministerio Público ${ }^{82}$.

- Tiene un plazo de prescripción de 4 años, contados desde la fecha de la actuación dañina.

- En caso de culpa grave o dolo, el Estado podrá, posteriormente, dirigirse en contra del fiscal o funcionario para exigirle lo pagado.

\section{ANÁLISIS JURISPRUDENCIAL}

La factibilidad de que la acción contemplada en el art. $5^{\circ}$ de la LOCMP sea la manera eficaz de obtener reparación en casos de errores injustificadamente erróneos o arbitrarios que se cometan en un proceso se puede apreciar en las siguientes sentencias, ambas pronunciadas por la Corte Suprema.

\section{1. "Ortega con Consejo de Defensa del Estado"83}

En cuanto a los hechos, estos son los siguientes: el día 29 de noviembre de 2002, en causa ante el Juzgado de Garantía de Temuco, el Ministerio Público solicitó en audiencia reservada la interceptación del teléfono de don Pablo Ortega Monsalva. Argumentó que éste se encontraba vinculado a una asociación

\footnotetext{
${ }^{81}$ VodAnOVIC, "Comentario", cit. nota n. 6, p. 5.

${ }^{82}$ VodanOVIC, "Comentario", cit. nota n. 6, p. 3.

${ }^{83}$ Ortega Monsalva, Pablo con Consejo de Defensa del Estado, Corte Suprema, 12 de julio de 2011, Rol No 2765-2009, Microjuris, MJJ28476.
} 
ilícita que tenía relación con el proceso que se estaba llevando a cabo (acerca de atentados Mapuches en el sur de Chile). Cabe señalar que el señor Ortega, a la fecha antes indicaba, tenía la calidad de abogado defensor en otros procesos relacionados con el Ilamado conflicto mapuche. El Ministerio Público en su solicitud no hizo presente dicha calidad, por lo que el tribunal acogió la solicitud exigiendo el estándar establecido en el art. 222 inciso $1^{\circ}$ del $\mathrm{CPP}^{84}$, que es claramente menor al que se debió haber sometido, es decir, el del inciso $3^{\circ}$ de este mismo artículo ${ }^{85}$. Una semana después, el señor Ortega asume como abogado en la causa en donde se decretó la medida intrusiva. Dos semanas después se realiza audiencia de cautela de garantías, en donde se dejó sin efecto la medida antes aludida.

Fruto de lo anterior, el señor Ortega deduce la acción contemplada en el art. $5^{\circ}$ de la LOCMP. En primera instancia ésta fue acogida, luego en la Corte de Apelaciones revocó la sentencia de primera instancia y, finalmente, la Corte Suprema conociendo el recurso de casación en el fondo, revocó la sentencia de segunda instancia, estableciendo el deber del Estado de responder por los daños sufridos por el afectado.

El afectado por la actuación del Ministerio Público fundamenta su pretensión, en primer lugar, en que dicho órgano (los fiscales a cargo del caso) si tenía conocimiento de su calidad de abogado relacionado con las causas del conflicto mapuche, por lo que su actuar fue deliberado e intencional, ya que al no comunicar al tribunal dicha característica, el estándar y parámetro con que resolvió no era el debido, como se dijo anteriormente, en caso de ser un abogado al que se le va a intervenir el teléfono, supone estándares más elevados, que los de cualquier persona. Y específicamente en el recurso de casación en el fondo deducido ante el Máximo Tribunal de nuestro país denuncia una interpretación errónea por parte de la Corte de Apelaciones de Temuco, del art. 222. En segundo lugar, denuncia la infracción de los artículos $2^{\circ}$ y $3^{\circ}$ de la LOCMP, es decir, que los fiscales en su actuar no cumplieron con los principios de objetividad y legalidad, y que, por lo tanto, en base al artículo $5^{\circ}$ de la misma ley, el actuar de los fiscales fue injustificadamente erróneo y arbitrario, el que le trajo graves

\footnotetext{
${ }^{84}$ Art. 222 inciso $1^{\circ}$ CPP.- Interceptación de comunicaciones telefónicas. Cuando existieren fundadas sospechas, basadas en hechos determinados, de que una persona hubiere cometido o participado en la preparación o comisión, o que ella preparare actualmente la comisión o participación en un hecho punible que mereciere pena de crimen, y la investigación lo hiciere imprescindible, el juez de garantía, a petición del ministerio público, podrá ordenar la interceptación y grabación de sus comunicaciones telefónicas o de otras formas de telecomunicación

${ }^{85} \mathrm{Art}$. 222 inciso $3^{\circ}$ CPP.- No se podrán interceptar las comunicaciones entre el imputado y su abogado, a menos que el juez de garantía lo ordenare, por estimar fundadamente, sobre la base de antecedentes de los que dejará constancia en la respectiva resolución, que el abogado pudiere tener responsabilidad penal en los hechos investigados.
} 
perjuicios personales y profesionales, afectándose su integridad síquica, puesto que dicha grabación fue difundida por los medios de comunicación, y que lo sindicaba como miembro de una asociación ilícita terrorista.

La Corte Suprema acogió la pretensión del señor Ortega y ordenó la indemnización por parte del Estado de Chile, por la conducta injustificadamente errónea y arbitraria del Ministerio Público. De dicha sentencia, cabe resaltar los siguientes considerandos:

Considerando $8^{\circ}$ "...El principio de objetividad impone al órgano persecutor un deber de lealtad, no sólo para con la defensa, sino que además se traduce en el deber de actuar de buena fe durante todo el procedimiento tanto como de investigar con igual celo tanto lo que puede incriminar al imputado o exculparlo de responsabilidad, lo que complementado con la vigencia de la sujeción a la ley de los funcionarios del Ministerio Público trae aparejado que las actuaciones que llevan a cabo no pueden afectar, derechos constitucionales o legales.

Hay un deber de actuar de los fiscales que debe ajustarse a los principios que informan su función, en este caso el de objetividad, que su actuar debe tener el mismo celo para determinar la responsabilidad de los imputados como autores del delito, como también para aminorar o exculpar su responsabilidad.

Considerando $9^{\circ}$ "Que dicho lo anterior, en el procedimiento penal el Fiscal podrá practicar determinadas diligencias sólo si cuenta con la autorización previa del juez de garantía cuando éstas importen una privación, perturbación o amenaza de los derechos garantizados al imputado o un tercero por la Constitución Política...".

Considerando $10^{\circ}$ "Que encerrando esta última medida (interceptación de las comunicaciones telefónicas) una afectación de considerable intensidad en el ejercicio de la defensa, se justifican los mayores estándares que exige el inciso $3^{\circ}$ del referido precepto para su autorización. Es decir, esta actuación del Ministerio Público no puede prescindir de normas esenciales del procedimiento, pues de lo contrario carece de legitimidad y su infracción genera la existencia de prueba ilícita".

Estos dos últimos considerandos establecen que el actuar del fiscal en este caso llevó a que se tomara una decisión sin contar con todos los elementos necesarios, lo que trae como consecuencia la afectación de derechos fundamentales de una persona, y así también la producción de prueba ilícita, la que finalmente no va a servir en el proceso.

Luego se establece con claridad cuál es el actuar del Ministerio Público que implica una conducta injustificadamente errónea o arbitraria.

Considerando $12^{\circ}$ "Que de esta manera, no obstante que el legislador dispuso de ciertos resguardos que estimó necesarios para intervenir las comunicaciones entre un imputado y su abogado, el Ministerio Público no respetó tales parámetros e impidió con ello que el órgano jurisdiccional resolviera acertadamente el 
conflicto que se suscita entre esa actuación y los derechos del imputado, entre éstos, el de la defensa jurídica".

De esta sentencia podemos concluir que la actuación del juez de decretar la intercepción telefónica de un abogado se debió al actuar doloso del fiscal del Ministerio Público, que escondió ante el Juez de Garantía la calidad de abogado y su relación con el proceso del señor Ortega.

Cabe hacernos la pregunta de si hubiera sido posible haber intentado la reparación a través de la acción del art. 19 № 7 letra i). La posibilidad queda abierta, pero lo que es seguro, que la elección de la acción utilizada por el señor Ortega para obtener la reparación fue la acertada, y que de acuerdo a la jurisprudencia de nuestra Corte, posiblemente si se hubiera intentado por el otro modo la respuesta no hubiere sido la misma. Nos hacemos otra pregunta: ¿se le debió exigir un mayor estándar de verificación de los requisitos del art. 222 del CPP al juez para decretar dicha medida? Aparentemente el Juez de Garantía fue engañado por el fiscal a cargo, por lo que es discutible plantear la responsabilidad del juez en este caso.

Un último elemento que Ilama la atención es que la Corte no se enreda en discusiones para determinar qué significa que el actuar del fiscal fue injustificadamente erróneo o arbitrario, sino que simplemente establece que en el cumplimiento de sus funciones no se adecuó a los principios de objetividad y legalidad, por lo tanto, su actuar trae consecuencias dañosas al particular, las cuales se deben indemnizar, marcando una clara diferencia cuando le toca resolver la acción contemplada en la Constitución.

\section{2. "Ossandón con Consejo de Defensa del Estado"86}

Este caso trata de una acción de indemnización por error judicial deducida por Marcela Ossandón por los siguientes hechos: es un caso de sustracción de identidad, en donde a la señora Ossandón en diciembre del año 2006 le robaron la cartera con todos sus documentos, ella el mismo día hizo la denuncia y procedió a bloquear todos sus documentos. 2 meses después una delincuente es sorprendida en un supermercado, en donde cargó mercaderías por un monto aproximado de cien mil pesos, al momento de pagar, presentó un cheque que parecía falso, fruto de aquello es que se procedió a su detención, y presentó ante la policía la cédula de identidad robada se la señora Ossandón. Con este nombre el Ministerio Público formuló acusación en su contra, y en procedimiento abreviado, se le condenó a 61 días de reclusión nocturna. El día en que debía presentarse para cumplir dicha condena, no se presentó, lo que motivo la fijación de una nueva audiencia para la revisión de este acuerdo. Al mismo

${ }^{86}$ Ossandón con Consejo de Defensa del Estado, Corte Suprema, 19 de marzo de 2009, Rol № 26402008. 
tiempo la afectada, descubrió la existencia de dicho delito en su prontuario, por lo que tuvo que tramitar la suspensión de los efectos de la sentencia impuesta en su contra, obtuvo una sentencia en contra de la suplantadora de identidad por estos mismos hechos, y logró que la Corte Suprema invalidara la sentencia y en su reemplazo se dictó sentencia absolutoria. Luego dedujo la acción antes mencionada para obtener una indemnización, pero aquella fue rechazada por la Corte Suprema.

De esta última sentencia se pueden resaltar los siguientes argumentos de la Corte establecidos en sus considerandos, en donde establece que la acción correcta para obtener la reparación por parte del Estado es la contemplada en el art. $5^{\circ}$ de la LOCMP.

Considerando $5^{\circ}$ "Que, finalmente, la Sra. Fiscal Judicial de este tribunal emitió su informe a fs. 157 y siguientes, en donde se advirtió que en el nuevo sistema de persecución la acción penal no está radicada en los tribunales, sino que en el Ministerio Público o en las demás personas que la ley señale en el artículo 53, de modo que no se trata de un error judicial, sino de la autoridad o personas que la ejercieron, lo que se encuentra regulado en el artículo $5^{\circ}$ de la ley $19.640^{\prime \prime}$.

Considerando $6^{\circ}$ "...En estas circunstancias, señala que tanto los funcionarios de la policía, como el Ministerio Público, debieron cerciorarse en forma previa, si la detenida era quien decía ser para lo cual contaba con todos los datos consignados en el Servicio de Registro Civil e Identificación...Termina la Sra. Fiscal, solicitando que se declare que hay mérito suficiente para hacer la declaración solicitada por el compareciente, pero sólo respecto de la actuación del Ministerio Público, toda vez que no lo hay en lo que corresponde a la sentencia condenatoria...".

Lo que se puede apreciar de estos dos considerandos es que del informe emanado por la Fiscal Judicial, ella establece que se está frente a una situación de error por parte del Ministerio Público (o la policía), pero en ningún caso de juez, ya que el actuar que ocasionó el perjuicio a la afectada fue fruto del actuar poco diligente de la policía y el fiscal. Termina estableciendo que procede la acción que busca la responsabilidad por actuaciones del Ministerio Público, pero no la que busca la responsabilidad por actuaciones del juez.

Luego se determina por parte de la Corte, que el error es imputable al Ministerio Público y no a la actuación jurisdiccional, por lo que la acción correcta es la del art. $5^{\circ}$ de la LOCMP, reconociendo la diferencia entre la responsabilidad del Estado-Juez y la responsabilidad administrativa del Estado.

Considerando $11^{\circ}$ "...tampoco es posible determinar que la resolución por la cual fue condenado como autora de hurto en grado frustrado, deviniera de un error judicial, que como también se anotó, la responsabilidad en la identificación de los imputados recae en los funcionarios de la policía..., y luego en el Ministerio Público". 
Considerando $12^{\circ}$ "...Esta disposición (art. $5^{\circ}$ de la LOCMP) señala un caso de responsabilidad administrativa del estado, mas, no jurisdiccional, puesto que naturalmente no puede generar esta clase de responsabilidad, la actividad de un órgano que tiene prohibido ejercer labores jurisdiccionales.

Puede esta responsabilidad estimarse complementaria a la norma del artículo $19 N^{\circ} 7$ letra i) de la Constitución Política, en el sentido de que los ciudadanos cuentan con una acción para exigir indemnización por los errores injustificados o por la arbitrariedad (aquí establece claramente que el término injustificadamente sólo se aplica al error y no a la arbitrariedad) y tienen ahora, además, una acción para dirigirse contra el Ministerio Público, que es el que presenta los cargos y dirige la investigación en los casos que la ley encomienda".

Reconoce, finalmente, lo ya planteado anteriormente, la coexistencia de estas dos acciones: una que busca la responsabilidad del Estado por su actuar jurisdiccional; y la otra que regula la responsabilidad administrativa del mismo por las actuaciones del Ministerio Público.

\section{EFICACIA DE LA NORMA DEL ARTíCULO $5^{\circ}$ DE LA}

LEY N $N^{\circ} 19.640$ VERSUS LA ACCIÓN DE INDEMNIZACIÓN POR ERROR JUDICIAL

\subsection{Principales diferencias}

Comparando ambas acciones estudiadas se puede determinar lo siguiente:

- Ambas acciones apuntan a un mismo objeto: obtener una indemnización, reparación, fruto del daño sufrido, ya sea por una resolución del órgano jurisdiccional o fruto de una conducta del Ministerio Público.

- Se trata de dos tipos de responsabilidades del Estado: la que establece la Constitución se enmarca dentro de la responsabilidad de Estado-Juez; en cambio, la contemplada en la LOCMP obedece a una responsabilidad Administrativa del Estado.

- Se tramitan de manera distinta: por un lado, es necesaria una calificación previa de la Corte Suprema para luego exigir la indemnización en sede civil, mientras que la otra se tramita directamente ante los tribunales civiles como cualquier acción ordinaria que busca resarcir y reparar los daños causados.

- Relacionado con lo anterior, "...la responsabilidad configurada conforme a dicha norma (Ministerio Público), no requiere, a diferencia de la señalada en la CPR para los tribunales de justicia en materia criminal, una calificación previa de admisibilidad de la Corte Suprema. El ciudadano, entonces, podrá intentar directamente ante el tribunal competente la acción de responsabilidad patrimonial contra el Estado"87.

${ }^{87}$ VodAnOVIC, "Comentario", cit. nota n. 6, p. 3. 
- La responsabilidad por las actuaciones injustificadamente erróneas o arbitrarias del Ministerio Público "...supone necesariamente una actuación dolosa o negligente del Ministerio Público. Es decir no hay responsabilidad objetiva" ${ }^{\prime \prime 8}$.

- En opinión del profesor Fernández $z^{89}$, "desentrañando el significado del artículo $5^{\circ}$ de la Ley Orgánica Constitucional del Ministerio Público, cabe hacer notar que es más amplio que la disposición constitucional, en cuanto no exige una actuación precisa del Ministerio Público en que pueda haberse causado el daño. Es más tampoco, requiere que dicha actuación haya quedado sin efecto después. Basta con que haya sido injustificadamente errónea o arbitraria".

\section{CONCLUSIÓN}

El presente trabajo partió fundamentalmente con el objeto de analizar y descubrir si frente a la irresponsabilidad del Estado, existente conforme al art. $19 \mathrm{~N}^{\circ} 7$ letra i) de la Constitución, es la acción contemplada en el art. $5^{\circ}$ de la LOCMP una solución, aunque sea en parte, para hacer efectiva la responsabilidad del Estado por los errores cometido en el proceso penal.

Hay que considerar un par de aspectos estudiados en este trabajo. En primer lugar, que la acción contemplada en la Constitución carece de eficacia, la poca precisión de sus palabras y la interpretación por parte de la Corta Suprema han Ilevado a configurar un área de irresponsabilidad, la del Estado por las actuaciones injustificadamente erróneas o arbitrarias que cometan los jueces en un proceso penal. En segundo lugar, que la acción de responsabilidad por las actuaciones del Ministerio Público no es una manifestación de la doctrina de la responsabilidad del Estado-Juez, ya que este órgano no ejerce funciones jurisdiccionales, por lo que cualquier eventual responsabilidad que se pueda configurar obedece a una responsabilidad administrativa por sus actuaciones.

Fruto de lo demostrado por la última jurisprudencia de la Corte Suprema, podemos decir que se está abriendo una oportunidad en nuestro ordenamiento jurídico para que los afectados en un proceso penal, puedan ver reparados sus derechos por los daños que sufran en un proceso penal. Si bien es posible que la acción del art. $5^{\circ}$ de la LOCMP pueda reemplazar a la acción constitucional, esto no se podrá dar siempre, ya que dependerá de la delgada línea existente entre las actuaciones del Ministerio Público y las actuaciones del juez. Como se puede apreciar en la sentencia de "Ortega con CDE", el acto en sí que causó el perjuicio fue la sentencia judicial, pero ésta obedeció a una actitud engañosa por parte del Ministerio Público. Y, por otro lado, en "Ossandón con CDE", es

\footnotetext{
${ }^{88}$ VodANOVIC, "Comentario", cit. nota n. 6, p. 3.

${ }^{89}$ Fernández, La Nueva, cit. nota n. 24, pp. 268-269.
} 
la misma Corte la que dice al particular que si quiere buscar indemnización por los perjuicios sufridos, tiene que buscar la responsabilidad por las actuaciones del Ministerio Público.

Un elemento que llama la atención para la elección de la acción de responsabilidad administrativa es que, según se desprende de la sentencia estudiada, no hay que hacer un mayor análisis sobre si la conducta del fiscal es injustificadamente errónea o arbitraria, sino que simplemente se configura al no haber éste seguido los principios que regulan su actuar.

En vista de lo anterior, en muchos casos será preferible, aun cuando sea dudoso si el actuar que causó el perjuicio es del tribunal o del fiscal, ejercer la acción del art. $5^{\circ}$ de la LOCMP, ya con ésta se tiene una mayor oportunidad de obtener una reparación, frente a la acción del art. 19 № 7 letra i), que sólo ha sido acogida cuatro veces en toda su historia.

\section{Bibliografía CITADA}

AgüERO, Mirta Noemí, Responsabilidad del Estado y de los Magistrados por Error Judicial, Buenos Aires, Editorial Ad-Hoc, 1995.

Caldera, Hugo, "Interpretación que la Corte Suprema ha dado a la norma constitucional sobre indemnización por error judicial", Gaceta Jurídica № 70, p. 10, y en Revista de Derecho Público, Facultad de Derecho, U. de Chile, No 37-38, 1985, pp. 345-364.

CAROCCA, Alex, "Reflexiones sobre el derecho a la reparación por error judicial en Chile a propósito de la solución amistosa ante la Comisión Interamericana de Derechos Humanos en el Ilamado caso La Calchona", Ius et praxis, 2002, pp. 641-660.

Cea Egaña, José Luis, "Fisonomía Constitucional del Ministerio Público de Chile", Revista de Derecho Valdivia, Universidad Austral, vol. 10 supl., 1999, pp. 59-66.

Cordero, Eduardo, "La administración del Estado en Chile y el concepto de autonomía", Contraloría General de la República 85 años de vida, Santiago, 2012, pp. 16-17.

Cordero VeGA, Luis Alberto, La responsabilidad de la administración del Estado, $2^{a}$ ed., Editorial LegalPublishing, Santiago, 2010.

Cordón Moreno, Faustino, Las Garantías Constitucionales del Proceso Penal, $2^{a}$ ed., Editorial Arazandi, Navarra, 2002.

Duce, Mauricio y Rııgo, Cristián, Procesal Penal, Editorial Jurídica, Santiago, 2007.

Desafíos del Ministerio Público Fiscal en América Latina, Centro de Estudios de Justicia de las Américas, Santiago, 2006. 
Fernández González, Miguel Ángel, La Nueva Justicia Penal frente a la Constitución, Editorial LexisNexis, Santiago, 2006.

García Mendoza, Hernán, La responsabilidad extracontractual del Estado: indemnización del error judicial, Editorial Jurídica ConoSur Ltda., Santiago, 1997, t. I, pp. 227-460.

GarRido Montt, Mario, "La indemnización por error judicial en Chile", lus et Praxis, 1999, vol. 5, pp. 473-482.

Hernández Emparanza, Domingo, "Error judicial: ensayo de interpretación constitucional", lus et Praxis, 1999, vol. 5, pp. 461-472.

Horvitz Lennon, María Inés; López Masle, Julián, Derecho Procesal Penal Chileno, Editorial Jurídica de Chile, Santiago, 2002, t. I.

Molina Guaita, Hernán, Derecho Constitucional, $8^{a}$ ed., Editorial LexisNexis, Santiago, 2008.

MundaCA, Hans, La responsabilidad del Estado por falta de servicio, Editorial Libromar Ltda., Valparaíso, 2001.

Otero, Miguel, El Ministerio Público, reforma constitucional y ley orgánica constitucional, Editorial LexisNexis, Santiago, 2002.

Pereira Anabalón, Hugo, "La responsabilidad del Estado por error judicial", Gaceta Jurídica № 275, 2003, pp. 7-15.

Precht Pizarro, Jorge, "Resolución injustificadamente errónea o arbitraria en la indemnización por error judicial", Estudios Constitucionales, 2004, vol. 2, número 001, pp. 175-180.

RieGo, Cristián, Reformas procesales penales en América latina: resultado de proyecto de seguimiento, CEJA, Santiago, 2005.

RodríGuez, Pablo, Responsabilidad Extracontractual, Editorial Jurídica de Chile, Santiago, 1999.

Tavoları Oliveros, Raúl, Instituciones del Nuevo Proceso Penal: cuestiones y casos, Editorial Jurídica de Chile, Santiago, 2005.

Vodanovic Schnake, Natalio, "Comentario de jurisprudencia: Aspectos de las indemnizaciones por error judicial y por conductas erróneas del Ministerio Público, con el nuevo sistema procesal penal". En: https://www.cde. cl/wps_migrated/wcm/connect/022b42004fbf7782baffbb46ce4e7365/18. pdf?MOD=AJPERES [visitado el 16/10/2012].

ZúÑIGA URBINA, Francisco, "La acción de indemnización por error judicial. Reforma Constitucional. Regulación infraconstitucional y jurisprudencia", Estudios Constitucionales, 2008, vol. 2, pp. 15-41. 